\title{
Reexistências na luta pelo lugar: Uma análise da hidrelétrica Candonga na Zona da Mata Mineira
}

Re-existence in the Struggle for Space: An Analysis of the Candonga

Hydro-electric Power Station (Zona da Mata Mineira)

Ré-existences dans la lutte pour l'espace: une analyse de l'hydroélectrique

Candonga (Zone de la Forêt Minière)

Marina de Oliveira Penido, Doralice Barros Pereira e Anabelle Lages

\section{(2) OpenEdition}

\section{Journals}

Edição electrónica

URL: http://journals.openedition.org/rccs/5232

DOI: $10.4000 /$ rccs.5232

ISSN: 2182-7435

\section{Editora}

Centro de Estudos Sociais da Universidade de Coimbra

Edição impressa

Data de publição: 1 Maio 2013

Paginação: 85-104

ISSN: 0254-1106

\section{Refêrencia eletrónica}

Marina de Oliveira Penido, Doralice Barros Pereira e Anabelle Lages, « Reexistências na luta pelo lugar: Uma análise da hidrelétrica Candonga na Zona da Mata Mineira ", Revista Crítica de Ciências Sociais [Online], 100 | 2013, colocado online no dia 28 outubro 2013, criado a 21 abril 2019. URL : http:// journals.openedition.org/rccs/5232 ; DOI : 10.4000/rccs.5232

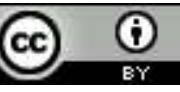




\section{MARINA DE OLIVEIRA PENIDO, DORALICE BARROS PEREIRA, ANABELLE LAGES}

\section{Reexistências na luta pelo lugar: Uma análise da hidrelétrica Candonga na Zona da Mata Mineira}

O artigo apresenta uma análise das contradições erigidas entre o reassentamento do Novo Soberbo, planejado pelo Setor Elétrico, e a realidade dos reassentados, atingidos pela hidrelétrica Candonga. As contradições existentes na relação reassentados/ /reassentamento expressam a oposição entre dois modos distintos de apropriar e significar o espaço: de um lado a racionalidade técnica e economicista do Consórcio Candonga, manifesta na concepção do reassentamento, em sua estruturação citadina; e de outro lado as práticas e representações dos atingidos, vinculadas a um modo de vida essencialmente rural. O reassentamento, como técnica para solução dos impactos originários do processo de deslocamento compulsório, engendra novas opressões e ameaças à reprodução da vida dos atingidos. Frente à desestruturação do modo de vida dos reassentados surgem mobilizações, resistências e reexistência na luta pelo lugar.

Palavras-chave: comunidades locais; energia hidroelétrica; injustiça ambiental; reassentamento.

Tantos pisam este chão que ele talvez um dia se humanize.

Carlos Drummond de Andrade

\section{Introdução}

No ideário de crescimento de hegemonia neoliberal, a construção de hidrelétricas tem submetido comunidades locais a um ciclo de exclusões que não termina; pelo contrário, se expande, na medida em que cada vez mais novos projetos econômicos vão sendo organizados e executados pelos investidores e empreendedores dos setores hegemônicos do capitalismo, como o setor minerário. Neste contexto, a energia tratada como um "bem público" torna-se mercadoria, cujo acesso é orientado segundo e exclusivamente pelas lógicas do mercado, sobretudo no caso do produtor industrial, que produz energia para uso próprio e privado. 
A racionalidade técnica e economicista que orientaram a instalação da usina hidrelétrica (UHE) de Candonga, localizada na Zona da Mata, Minas Gerais, Brasil, como se verá, restringiu o modo de vida e os meios de subsistência dos moradores a meros "imóveis" e "propriedades", passíveis de compensação e realocação, esvaziando o espaço dos sentidos do lugar (Oliveira, 2005). Para os atingidos, por sua vez, não se trata de "imóveis", de "propriedades", e sim da terra, da casa, do quintal, do rio como lugar da vida. Neste sentido, São Sebastião do Soberbo - lugar da memória, "casa da gente", "da fartura”, "da riqueza", "da segurança”, "da estabilidade" se contrapõe ao Novo Soberbo - "espaço da escassez", "da falta”, "da instabilidade", "das incertezas". A construção de São Sebastião do Soberbo e do Novo Soberbo, pelos reassentados, como par de opostos passa no mínimo pelo contraste entre o "rural" e o "urbano". Tal contraste reforça as representações ideologizadas elaboradas em torno do modo de vida no "Soberbo Velho", arcaico, atrasado em oposição às condições de vida no reassentamento do Novo Soberbo, moderno, avançado, civilizado.

As iniciativas de reconstruir o reassentamento como lugar têm resultado em práticas concretas de apropriação e ressignificação, que expressam resistências e "resíduos de ruralidade", que por sua vez emergem da necessidade de sobrevivência e da atividade imaginativa dos reassentados precipitada pelo devir da realidade. Como menciona Berman (1986:330), "o processo de modernização, ao mesmo tempo em que nos explora e nos atormenta, nos impele a apreender e a enfrentar o mundo que a modernização constrói e a lutar por torná-lo nosso mundo".

A partir da análise de histórias individuais - socialmente construídas num cenário de transformações decorrentes do deslocamento compulsório - busca-se investigar as práticas sociais dos reassentados, os impasses, as permanências e rupturas com antigas práticas relacionais, discursivas e representativas (Thompson, 1992). Foram focalizados os conflitos advindos da atuação do Consórcio Candonga face aos sentidos de lugar, submetendo-os às relações verticais do poder global hegemônico. Os conflitos se manifestam pela/o interação/intercruzamento entre visões de mundo, práticas sociais e interesses distintos. De um lado, os valores do "progresso", duplamente representados na propalada necessidade de instalação dos empreendimentos hidrelétricos para o crescimento do país e na visão dos técnicos elaboradores dos reassentamentos, defensores das "benesses", oriundas de uma organização mais "civilizada" para os atingidos. Do outro lado, estão os valores da tradição, alicerces do modo de vida rural dos moradores das margens do rio, cujas referências temporais e espaciais estão associadas a outros ciclos, como por exemplo aos ciclos da natureza (Rebouças, 2000). Desse dissonante 
intercruzamento emergem ameaças e riscos que esfacelam o modo de vida, as condições e os meios de sobrevivência dos atingidos (ibidem).

$\mathrm{Na}$ presente análise, o lugar se refere à materialização da globalização, cujo conteúdo é redefinido e as particularidades não são totalmente anuladas. Ele permite pensar os conflitos do mundo moderno, o processo de produção e reprodução das relações sociais e suas espacializações que extrapolam as fronteiras do lugar até então vigentes (Carlos, 1996). Nesse sentido, o significado de lugar está delineado pela relação local-global, na medida em que a diversidade, as formas e a novidade dos seus conteúdos estão aí para reclamar novas interpretações dessa realidade.

A primeira parte do artigo traz elementos que contextualizam o deslocamento compulsório dos moradores e de suas práticas do "Soberbo Velho" para o reassentamento do "Novo Soberbo", do rural para o "urbano". $\mathrm{Na}$ segunda parte, buscou-se melhor entender a racionalidade que, presente na concepção e construção do reassentamento, pretendeu conformar este espaço à óptica do Setor Elétrico, deteriorando e se sobrepondo ao modo de vida dos atingidos. Por fim, a terceira parte enfatiza a discussão da categoria lugar estabelecendo os nexos, impasses e descompassos entre a "ordem distante" e a "ordem próxima", exemplificando com relatos e depoimentos dos reassentados na sua lida com o "novo".

\section{O deslocamento do "Soberbo Velho" para o "Novo Soberbo"}

No contexto das privatizações da segunda metade dos anos 1990, a hidrelétrica Candonga se insere na conjuntura de empreendimentos financiados por empresas privadas, a Novelis e a Companhia Vale do Rio Doce. ${ }^{1}$ Ambas, com a promulgação da nova lei para concessão de serviços públicos editada em 1995, ingressaram no mercado de geração de energia elétrica em Minas Gerais (Lemos, 1999; Vieira, 2000). Com um propósito tão mercantil e individualista, Bermann (2007: 149) questiona "a legitimidade da expropriação para fins de atividades consideradas privadas, seja na condição de produtor independente, seja para fins de consumo exclusivo" de tal produção energética.

\footnotetext{
${ }^{1}$ A Novelis do Brasil, subsidiária da Novelis Inc., opera desde janeiro de 2005, após desmembramento dos negócios laminados da Alcan em todo o mundo. Sediada em Atlanta (EUA), a empresa mantém, em diversos continentes, atividades de mineração de bauxita, refinação, produção, laminação e reciclagem de alumínio e geração de energia hidroelétrica (Fonte: http://www.novelis.com/ pt-br/Paginas/Who-We-Are.aspx. Consultada a 20.09.2013). A outra consorciada, a Companhia Vale do Rio Doce (criada em 1942 e desde 2007 denominada Vale) dedica-se à mineração e ao tratamento de materiais minerais e detém grandes investimentos em energia elétrica, com nove usinas no Brasil possui potência instalada total de $3364 \mathrm{MW}$. A energia produzida destina-se a seu consumo próprio e à venda do excedente no mercado (Jornal Estado de Minas, 21.08.2005, p. 14).
} 
A construção da hidrelétrica Candonga, na microrregião de Ponte Nova, entre os municípios de Rio Doce e Santa Cruz do Escalvado, ocorreu entre junho de 2001 e março de 2004, a jusante da junção do rio do Carmo com o rio Piranga, no Rio Doce. O reservatório da usina alagou um total de 286 ha na microrregião de Ponte Nova e afetou diretamente centenas de famílias nas duas margens do rio Doce:

No lado direito, no distrito de São Sebastião do Soberbo, foram afetadas aproximadamente 270 pessoas residentes em quase 120 domicílios, além de outras cinco famílias residentes na área do canteiro de obras, em Pedra do Escalvado, incluindo o eixo da barragem. Na margem esquerda, no município de Rio Doce, cerca de dez famílias de trabalhadores rurais agregados, residentes na Fazenda Marimbondo, foram deslocados. (Pinto, 2005: 73)

Outras famílias, apesar de não terem sofrido com o deslocamento compulsório, vivenciaram processos de desestruturação de suas formas e meios de trabalho, em especial os meeiros e garimpeiros, não só em São Sebastião do Soberbo, como também no município de Rio Doce e nas comunidades de Jerônimo, Santana do Deserto e Marimbondo. O distrito mais atingido pela construção da barragem, ${ }^{2}$ São Sebastião do Soberbo, era um típico povoado ribeirinho, formado por famílias, em sua maior parte, de baixa renda e baixa escolaridade (Pinto, 2005). A dinâmica da economia local, rural em essência, vinculava-se à agricultura de base familiar, à pesca e ao garimpo ao longo do rio. $\mathrm{Na}$ época da seca, os moradores exploravam, no rio, a faiscação atrás de ouro como forma de geração de renda. Nos períodos chuvosos, grande parte das famílias trabalhava a terra em propriedade própria e/ou como meeira.

Quanto aos trâmites institucionais para liberação das licenças, a omissão de informações aos atingidos, somada aos mecanismos de controle social como coerção e cooptação, garantiram ao Consórcio Candonga a rápida concessão das Licenças Prévia (LP) e de Instalação (LI) da hidrelétrica. Com base no parecer da Fundação Estadual do Meio Ambiente (FEAM), o Conselho Estadual de Política Ambiental (COPAM), em 29 de agosto de 1999, concedeu a Licença Prévia aos empreendedores. Para a obtenção da

\footnotetext{
2 São Sebastião do Soberbo, antigo povoado do Soberbo, pertencia à Santa Cruz do Escalvado, cuja população rural municipal era de 3262 hab., enquanto a urbana de 1730, totalizando 4992 habitantes (IBGE, 2010), em uma área total de $259,1 \mathrm{~km}^{2}$. O reservatório da usina inundou 286 ha da área rural de Santa Cruz de Escalvado, cobrindo completamente São Sebastião do Soberbo, a $3 \mathrm{~km}$ da sede municipal de Rio Doce.
} 
Licença de Instalação, o Consórcio apresentou no início de 2001 o Plano de Controle Ambiental (PCA), elaborado pela empresa DELPHI. A licença foi concedida pela CIF/COPAM em 29 de junho de 2001. ${ }^{3}$

Até à concessão da Licença de Instalação em 2001, o Consórcio Candonga ainda não tinha esclarecido os moradores como seria o projeto do reservatório, menos ainda do reassentamento. As incertezas e a ansiedade desorganizaram o cotidiano das pessoas. Elas deixaram de plantar, de trabalhar, de construir e reparar casas e benfeitorias em suas propriedades, face ao risco eminente de terem os seus bens materiais submersos pela barragem. Por meio de estratégias de controle social como cooptação das lideranças locais e negociações individuais, manteve-se uma aparente e precária participação da comunidade no processo de implantação do empreendimento. Tais estratégias, na verdade, também contribuíram para esfacelar e retrair as tentativas concretas de mobilização e resistência dos atingidos.

Após a concessão da Licença de Instalação, a comunidade mobilizou-se para formar a primeira "Associação de Atingidos", a fim de reivindicarem os seus direitos. Todavia, desde o seu nascedouro, a associação agregou lideranças cooptadas, movidas muito mais pelos interesses e apelos dos empreendedores e dos segmentos locais dominantes, como expõe o relato a seguir:

A Associação foi muita enganação, porque eles não representavam a gente nas reuniões, nem nas cobranças nos órgãos do meio ambiente. Eles estavam todos juntos com o Consórcio e até nós atinarmos do caso, ficamos feitos cordeirinhos... Só amém, amém... A gente calado e eles não falavam nada! Estavam ali só pra garantir o deles [...]. (Entrevista com reassentado de Novo Soberbo, militante do MAB, 47 anos, em 28.02.07)

Descrentes com a atuação da Associação, em 2003, outro movimento de resistência dos atingidos pela UHE Candonga foi iniciado, contando a partir de então com uma articulação junto ao Movimento dos Atingidos por Barragem (MAB) e ao Núcleo de Assessoria às Comunidades Atingidas por Barragens (NACAB). ${ }^{4} \mathrm{O}$ movimento veio questionar as medidas compensatórias, reflexo da forma como as negociações foram conduzidas e,

\footnotetext{
${ }^{3}$ Mais informações consultar o Relatório "Atingidos e barrados: as violações de direitos humanos na hidrelétrica Candonga”, organizado por Barros e Sylvestre, 2004.

${ }^{4}$ O NACAB é uma ONG vinculada à Universidade Federal de Viçosa, com atividades de pesquisa e extensão voltadas para a assessoria de comunidades atingidas por barragens, principalmente na região da Zona da Mata Mineira.
} 
até então, legitimadas pela intermediação da Associação de Atingidos. Encarado quase como um aspecto irrelevante decorrente de uma política governamental marcada por decisões tecnocráticas, encerradas em gabinetes, o processo de negociação foi extremamente conturbado e pontuado por injustiças que repercutem até ao momento. O caráter secreto e personalizado das negociações, sob o pretexto de consignar as necessidades específicas de cada família, foi outra estratégia do Consórcio para desarticular e manipular a comunidade:

... então, eles vinham e... e diziam que o meu direito de meeiro e garimpeiro custava no total de tudo... dava 10 mil e que eu teria casa de permuta aqui [Novo Soberbo]. Aí eles vinham com a conversa fiada, dizendo que eu era chegado, que é... que se importavam com a minha família, que iam fazê um agrado e que era só pra mim... tá, então aí eles diziam "não comenta com seu vizinho, nem com ninguém, é só pra você amigão!" Então o povo que achava que tinha feito boa negociação, no começo ficava calado, com medo de mela a negociação ou com medo deles leva as coisas pra justiça, porque eles ameaçava assim... (Entrevista com reassentado, 54 anos, em 25.02.07)

Em verdade, os moradores não sabiam ao certo estipular, conforme o mercado, o valor de suas propriedades, tornando-se frágeis e vulneráveis frente às ofertas dos "negociadores", o que resultou em arbitrariedades nas avaliações dos técnicos contratados pelo Consórcio:

As pessoas não entendem como um terreno onde uma família viveu durante 60 anos possa ser valorizado em $\mathrm{R} \$ 520,00$ e um chiqueiro que acomodava três porcos possa valer R\$3.000. É difícil de entendermos isso. Então, queremos renegociar para entender isso. (COPAM/CIF, 2002; ata de reunião em 14.03.03)

A ausência de uma padronização nos critérios de avaliação das propriedades ocasionou embates e rivalidades não só entre o Consórcio e os atingidos, mas ainda entre os próprios moradores do "Soberbo Velho". As comparações foram constantes entre o que um e outro morador havia recebido como compensação aos bens materiais que seriam inundados pelas águas da barragem. Os atingidos que criticaram as arbitrariedades das negociações apontaram as lideranças cooptadas, os familiares e amigos das autoridades públicas locais (prefeitos e vereadores) e os maiores proprietários de terra da região como os verdadeiros favorecidos pelas indenizações. Nessa configuração viciosa, caracterizada por "políticas" clientelistas, a luta pela apropriação do território revela-se injusta e desigual, um "jogo político" 
previamente definido pelas relações pessoais e pelas posições privilegiadas na geometria do poder local.

A "negociação", carregada de conotações relacionais e "democráticas", dissimulou a realidade de dominação e expropriação dos atingidos, arquitetada através da ação capciosa dos empreendedores. A FEAM, em relatório técnico, questionou:

Importa destacar, inclusive, em reforço ao exposto, que não rara manifestação queixosa vinda de diferentes membros da comunidade atingida até a FEAM, deixava evidente a reminiscência de um passivo social daquela primeira fase executiva do programa, consubstanciada por acordos individuais fechados precipitadamente, sem guardar a maturação e avaliação devidas, decorrentes, entre outros, de utilização de métodos de persuasão pouco ortodoxos por parte de prepostos do empreendedor na desapropriação de terras, de predomínio de um baixo nível de informação sobre direitos e benefícios sociais assegurados legalmente no licenciamento ambiental de hidrelétricas em geral e de conhecimento superficial insuficiente dos projetos de mitigação de impacto social e econômico do PCA. (FEAM/DIENE, 2004: 56)

Segundo Harvey (1980: 67), a própria "heterogeneidade de valores culturais e sociais pode tornar impossível aos grupos chegarem a uma posição de negociação válida". As insatisfações com as "negociações" individuais e as evidências dos benefícios auferidos pelas lideranças da, já desestruturada, Associação de Atingidos, aumentaram durante a execução do projeto de reassentamento. Antes da concessão da licença de operação, o relatório da Fundação Estadual do Meio Ambiente de Minas Gerais assinala: "a FEAM teve a oportunidade de registrar um dos mais elevados índices de estresse social relacionados à implantação de empreendimentos hidrelétricos submetidos ao licenciamento ambiental" (FEAM/DIENE, 2004: 96).

As obras da barragem cumpriam um cronograma de ritmo frenético e as da "nova cidade" nem sequer haviam começado, o que potencializou ainda mais a eclosão de conflitos. O estopim da revolta se deu quando os atingidos perceberam as condições habitacionais do Novo Soberbo: residências pequenas, construídas com materiais de má qualidade e sem colunas de sustentação, muitas delas abaixo do nível da rua; quintais pequenos e com terra improdutiva; além de a organização e funcionalidade espacial do reassentamento se apresentar muito diferenciada daquela do lugar de vivência anterior, desestruturando as suas relações de produção e de reprodução social anteriores. 
Por essa razão, em abril de 2004, a então Juíza da 2. ${ }^{a}$ Vara Cível da Comarca de Ponte Nova, nos autos da Ação Civil Pública ${ }^{5}$ interposta pelo Núcleo de Assessoria às Comunidades Atingidas por Barragens (NACAB), concedeu liminar contrária ao início da operação da barragem. $\mathrm{Na}$ decisão que suspendeu o enchimento do reservatório, a magistrada considerou que por "não terem os réus concluído todas as medidas socioambientais previstas para a implantação e, não tendo os requisitos desta sido cumpridos, não há como terem deferida a operação". Em relação ao perigo de prejuízo irreparável, sustentou que "uma vez ocorrido o enchimento do lago, não haverá como averiguar as pendências existentes, bem como o cumprimento ou não destas". Nesse entender, deferiu o pedido determinando ao Consórcio Candonga que se abstivesse de encher o reservatório até que todas as pendências socioambientais fossem solucionadas.

Contudo, a decisão que obstou o enchimento do reservatório foi cassada pelo Tribunal de Justiça de Minas Gerais. Na nova decisão, o desembargador (acatando o parecer do Ministério Público) sustentou que o Consórcio Candonga ofereceu caução no valor de R\$ 1393 688,50, garantindo o ressarcimento de eventuais danos. O magistrado salientou, ainda, que as "pendências ambientais apontadas não [guardariam] qualquer relação com o enchimento do lago". E também que

a Usina Hidrelétrica Candonga é hoje uma realidade irreversível e consolidada, não existindo qualquer razão para se impedir o enchimento do reservatório da usina, sendo certo também que a geração de energia ali esperada visa à satisfação de necessidades prementes do país, sobretudo, se advier o tão esperado espetáculo do crescimento. ${ }^{6}$

Assim, a não participação dos atingidos nos processos decisórios, além da não observância de outras normas do procedimento administrativo ambiental, permite-nos afirmar que houve uma improvisação despótica nas diferentes fases de trato com o coletivo por parte dos empreendedores. Como expõem os registros a seguir, a construção do reassentamento deu-se de forma autoritária:

A construção do Novo Soberbo foi iniciada de forma fechada, sem qualquer acesso da comunidade para verificação. Quando esse acesso foi permitido, por pressão da

\footnotetext{
${ }^{5}$ O mérito da Ação Civil Pública n. ${ }^{\circ} 052104$ 032157-7, em trâmite na 2. ${ }^{a}$ Vara Cível da Comarca de Ponte Nova, foi julgado improcedente no dia 27 de maio de 2009, pela atual juíza da comarca de Ponte Nova. ${ }^{6}$ Fonte: http://saladeimprensa.vale.com/pt/versao_impressao/prt_detail.asp?tipo=1\&id=12497. Consultado a 25.01.2010.
} 
comunidade, verificou-se o quê? [...] São casas que não possuem colunas, em que a rua está no nível do telhado. Você sai na porta da sua cozinha e, daí a meio metro, você tem um paredão de barro, que é o seu terreno, que acaba ali. E a rua, na altura do telhado. O consórcio disse que aquilo estava muito bom, que a comunidade tinha aprovado aquilo. O tamanho das casas também foi objeto de vício no processo de escolha, porque foi apresentada uma planta de engenharia para uma comunidade sabidamente despreparada para analisar esse tipo de documento; pessoas com pouca escolaridade, pessoas de idade que não têm idéia do que seja $47 \mathrm{~m}^{2}$ ou $120 \mathrm{~m}^{2}$. E por aí vai o descalabro. (Representante dos atingidos; COPAM/CIF, 2002)

[...] o pessoal não podia nem acompanhar a obra do reassentamento, as negociações estavam confusas, muitos negociadores e foi tudo acertado nos bastidores, debaixo dos panos [...]. Um dos estopins foi o episódio "das casas no buraco". As casas foram construídas muito abaixo do nível do passeio, da rua, o que acabou por gerar insatisfações tão grandes que resultou em mobilizações e na derrubada e reconstrução dessas casas pelo Consórcio. (Entrevista realizada com militante do MAB de Ponte Nova, em 23.02.07)

A insatisfação com o reassentamento invocou com mais contundência a resistência das famílias à realocação. Somente no final de abril de 2004 os atingidos mudaram para as residências do Novo Soberbo, restando apenas 14 famílias em São Sebastião do Soberbo (Pinto, 2005). Estas, por força de uma ordem judicial, foram despejadas, com autorização do governo estadual e por meio de significativo aparato policial. ${ }^{7}$ Assim, com a legitimação do Estado, no dia 3 de maio de 2004 os moradores que resistiam à mudança foram expulsos por 190 soldados armados:

Eram muitos policiais, uns quase 200, eles estavam armados e vieram junto caminhões de mudança, tratores e outras máquinas para demolir o Soberbo... Trataram a gente pior que cachorro vira-lata [...]. Os policiais vieram, arrombaram as portas das casas, tinha gente que não tava, então, as coisas dessas pessoas foram pegadas e jogadas dentro do caminhão de mudança sem a menor consideração, o menor cuidado... Aí quebraram coisas, o meu guarda-roupa e coisa de muita gente daqui. E depois que pegou os trem de todo mundo jogaram lá na porta das casas do Novo Soberbo, assim... Jogado mesmo. (Entrevista com reassentada, 49 anos, 23.02.07)

\footnotetext{
${ }^{7}$ Rancière (1996: 372) relaciona a noção tradicional de política e polícia, porque esta não "é simplesmente um conjunto de formas de gestão e de comando. É mais fundamentalmente o recorte do mundo sensível que define, no mais das vezes implicitamente, as formas do espaço em que o comando se exerce". A manutenção da ordem necessária, a partir do poder da polícia, corresponderá à anulação da política, cuja realização, para além de concepções redutoras e habituais, se dá através do dissenso, do conflito e da luta de classes.
} 
$\mathrm{O}$ uso da força, presente e naturalizada nas relações sociais, afastou a possibilidade de recursos para fora da esfera de mando. O comprometimento do poder estatal e do judiciário (que cassou a liminar concedida pela juíza de Ponte Nova) alimentou ainda mais a violência, na medida em que socialmente se construiu uma expectativa de que não seria possível resolver nenhuma pendência fora das "regras tradicionais".

\section{O diletantismo e a espacialização do reassentamento}

Os programas de reassentamento, denominação não necessariamente fundada em conteúdo, ou diretrizes de atuação aparecem nos Estudos de Impacto Ambiental (EIA) e nos Relatórios de Impacto Ambiental (RIMA) pretendendo compor o rol de medidas mitigadoras, enquanto forma antecipatória de relativizar/dissimular os impactos de empreendimentos geralmente controversos do ponto de vista socioambiental. A avaliação técnica dos EIA-RIMAs ao desconsiderar a vida, as condições e o modo de vida dos atingidos, mais do que dar lugar a uma representação ideológica da realidade, elaboram formas de assegurar a viabilidade do empreendimento sob o menor custo (notadamente financeiro):

[...] a recusa da condição de sujeito histórico às populações afetadas, a postulação de que o único sujeito efetivo - capaz de subjetividade, de projeção e de ação - é o empreendedor/empreendimento, mais além de uma representação ideológica da situação concreta, constitui, pois, condições para o sucesso do projeto, quanto à validação das previsões de impacto social. (Vainer, 1993: 192)

O empreendimento como um fato consumado, imprescindível ao desenvolvimento do país, reduz e elimina qualquer tipo de indeterminação. A certeza inexorável de que o projeto será implementado anula as possibilidades do instituinte através do próprio discurso técnico, "competente", que sustenta ilusões de veracidade e objetividade incontestável ao que é dito (Chaú, 1981: 7). O discurso técnico, ao legitimar o empreendimento frente à opinião pública, mostra que, em decorrência da suposta neutralidade científica, a ciência pode fornecer os meios adequados para se atingir um fim já estabelecido (Vieira, 2000). Diversos autores, como Marcuse (já em 1964), discutem a alegada neutralidade, bem como a apropriação e a

\footnotetext{
${ }^{8} \mathrm{Na}$ esfera política, o uso indiscriminado da força, em vários momentos da história, remete-nos à tradicionalidade e legitimidade a ele concedidas. Nos embates ideológicos pelo poder, a radicalização das partes envolvidas na defesa de seus interesses políticos sai, muitas vezes, do campo das ideias para o da ação violenta (Dos Santos, 1992).
} 
imposição de significados ao espaço (por exemplo, Lefebvre, 2000; 2008; Acselrad, 2004; Acselrad et al., 2004; Zhouri et al., 2005).

No reassentamento de Novo Soberbo, a valorização de concepções e representações de espaço ligadas a um ambiente urbano torna-se evidente na prevalência de uma certa ordem e de uma certa estética condizentes com sistemas simbólicos citadinos. São Sebastião do Soberbo, apesar de não possuir uma "modernidade" estética das casas, era um lugar com todos os elementos básicos à produção e reprodução do modo de vida dos seus moradores. No "Soberbo Velho", estavam presentes uma ordem/desordem construtivas, marcadas por uma historicidade social e espontaneamente firmadas na íntima relação com o espaço, o que por sua vez o definia como lugar.

As indenizações repassadas na forma de infraestruturas urbanas, no reassentamento, traduzem o tratamento dado aos atingidos como "beneficiários" do empreendimento (Rebouças, 2000). Assim, o projeto da "nova cidade", o reassentamento do Novo Soberbo, foi apresentado à FEAM como o de um novo distrito com área comercial e industrial (atividades inexistentes no antigo povoado) destinada a gerar crescimento econômico para a região de Santa Cruz do Escalvado. Com perspectiva tão promissora, os contemplados só poderiam ser "beneficiários", visão que obscurece, confunde a categoria de "atingidos" pelo empreendimento.

Inegavelmente, a estrutura material do reassentamento implica num determinado elenco de apropriações possíveis, o que torna evidente que, na concepção do Novo Soberbo, estão embutidas concepções e formas de apropriação do espaço que deslegitimam e se sobrepõem a outras apropriações e concepções possíveis. Assim, o reassentamento tornou-se uma determinação e não uma possibilidade. O Novo Soberbo voltou-se única e exclusivamente para a função de residir:

Aqui fico quieto porque não tenho o que fazer, porque quando aparece um serviço já tem uma turma lá... Eu já tô velho... Mas e eles [filhos]? Eu com pouquinha terra vou deixar o que pra eles? Eles vão ficar como? Plantar é o que eles aprenderam, porque eles não têm grande estudo. E serviço aqui não tem. Vive de quê? (Entrevista com reassentado, 62 anos, em 25.02.07)

Aqui só tem buteco mais nada, e não sei pra que tanto buteco no centro comercial [...]. E essa juventude à toa, os homem tudo à toa, sem dinheiro, a tentação do buteco é grande [...]. Aqui é ruim demais não tem um buteco de verdura, um açougue, uma farmácia... (Entrevista com reassentada, 75 anos, em 24.02.07) 
Como visto, o reassentamento está muito aquém das necessidades das pessoas que nele residem. Apesar de seu formato citadino, a sua estruturação não permite que o urbano, na vivacidade das relações, se realize. O Novo Soberbo é urbano somente em sua aparência, na ambientação conformadora de novos comportamentos e modos de uso e consumo. Construiu-se uma "nova cidade" que concretizou a ausência do direito à cidade (Lefebvre, 1991). Assim, o reassentamento não favoreceu o urbano, nem o rural; não serviu nem às necessidades, nem à reprodução do modo de vida dos seus moradores: a "capacidade - a de acolher os eventos - não pode ser medida apenas em termos ergonômicos ou de disposição adequada de equipamentos e mobiliários, porque as atividades são desenvolvidas por pessoas" (Malard, 2006: 125, grifo nosso).

Evidenciaram-se, portanto, nesse espaço, contradições entre as "ideologias" da tecnocracia esterilizadora, e aquilo que se tem como útil e importante para os atingidos, reflexo de seus valores, de suas representações e apropriações efetivadas no plano do lugar.

\section{Lugar: entre a ordem distante e a ordem próxima}

O lugar constitui a dimensão da existência que se manifesta através de um cotidiano compartilhado entre as mais diversas pessoas, empresas e instituições, configurando mais do que um cenário de cooperação e conflito, a base da vida em comum (Santos, 2008). No movimento global-local, o que Santos denomina "mundo vivido" vigora no conceito de lugar por meio de coexistências:

no lugar, nosso Próximo, se superpõe, dialeticamente ao eixo das sucessões, que transmite os tempos externos das escalas superiores e o eixo dos tempos internos, que é o eixo das coexistências, onde tudo se funde, enlaçando definitivamente, as noções e as realidades de espaço e tempo. (2008: 322)

O processo de deslocamento e realocação compulsória, ocasionado pela implantação de hidrelétricas, tem provocado a perda dos lugares de vivência e a expulsão dos atingidos para um espaço estranho/estranhado, concebido por parâmetros operacionais desvinculados de suas vidas e das suas formas/modos de reprodução social. A partir da abordagem de lugar de Carlos (1996), é possível dizer que os reassentamentos, a reboque da construção de usinas hidrelétricas, expressam a materialização da globalização, da modernidade, de processos político-econômicos que atravessam as fronteiras nacionais (manifesta, por exemplo, através da presença de empresas transnacionais no segmento hidrelétrico), engendrando novas 
combinações de espaço-tempo. As formas e funções espaciais e o modo de vida dos atingidos sofrem, assim, constantes transformações provenientes do processo de utilização "desenfreada" e acelerada do espaço que se vincula à acumulação de capital, comprometendo as condições de vida historicamente estabelecidas. ${ }^{?}$

A relação global-local, contraditória e permeada por desequilíbrios, no Novo Soberbo, desvela-se nas sobreposições da ordem distante, global, sobre a ordem próxima:

a ordem global funda as escalas superiores ou externas à escala do cotidiano. Seus parâmetros são a razão técnica e operacional, o cálculo de função, a linguagem matemática. A ordem local funda a escala do cotidiano, e seus parâmetros são a co-presença, a vizinhança, a intimidade, a emoção, a cooperação e a socialização com base na contigüidade. (Santos, 2008: 339)

Assim, o caminho que se abre à análise é pensar o cotidiano, ${ }^{10}$ no qual se realizam o local e o mundial, onde se tecem maneiras de ser, conjuntos de afetos, modos de vida, elementos culturais e simbólicos dos indivíduos e dos grupos sociais (Carlos, 1996). Assim, o cotidiano se reporta às identidades. Todas elas, contidas no espaço e no tempo simbólicos, elucidam o que Edward Said (1990) denomina "geografias imaginárias": "suas paisagens características, seu senso de 'lugar', de 'casa/lar', ou heimat, bem como suas localizações no tempo - nas tradições inventadas que ligam passado e presente, em mitos de origem que projetam o presente de volta no passado" (Said, 1990 apud Hall, 2006: 72). Tais entrelaçamentos temporais anunciam a relação "lugar-lar" que vincula e contrapõe a vida no "Soberbo Velho" à vida no "Novo Soberbo":

Eu gostava muito do Soberbo Velho, tinha um terreninho, engordava porco, tinha muito peixe [...] Lá era um lugar bom pra mim e pra minha família e pra nós tudo aqui. Era pobre, não vô fala que era um lugar de rico, mas era o suficiente [...] Foi muito triste ter que sair de lá, a gente sai mas não esquece a violência $[\ldots]$

\footnotetext{
${ }^{9}$ A partir da industrialização/urbanização, mesmo os espaços tidos como rurais são controlados pelo espaço urbano, onde toda a sociedade, tendencialmente, se urbaniza, o que não significa o fim do rural (Lefebvre, 1975).

10 "O cotidiano é aquilo que nos é dado a cada dia (ou que nos cabe em partilha), nos pressiona dia após dia, nos oprime, pois existe uma opressão do presente. Todo dia, pela manhã, aquilo que assumimos, ao despertar e o peso da vida, a dificuldade de viver, ou de viver nesta ou noutra condição, com esta fadiga, com este desejo. O cotidiano é aquilo que nos prende intimamente, a partir do interior. É uma história a meio-caminho de nós mesmos, quase em retirada, às vezes velada" (De Certeau, 1996: 31).
} 
é aquele trem, a gente vai pra outro canto, pro Soberbo Novo e pro Soberbo de diabo a quatro, mas não tem lugar melhor que a casa da gente. Então, pra nós que lidava na terra e no rio não tinha lugar melhor que o Soberbo Velho não. (Entrevista com reassentado, 54 anos, em 25.02.07)

Eu queria ter minha vida lá e não queria morrer aqui. Lá eu tava ambientado, tinha fartura [...] Todo mundo trabalhava, tinha tranqüilidade, não tinha tanta preocupação com o meio de sobrevivência. Uma comunidade que não tem meio de sobrevivência, o que esperar da vida? Não tem serviço aqui. Aqui eu fico mais doente que lá. (Entrevista com reassentado, 33 anos, em 24.02.07)

A primeira fala, ao associar o "Soberbo Velho" à "casa da gente", expõe, subjetivamente, um sentimento de familiaridade com aquele espaço, lugar destinado à reprodução de um modo de vida arraigado à terra e ao rio. O Novo Soberbo aparece, então, como um contraponto para o reassentado, o "outro canto", da esfera do "diabo a quatro", um local distante da "casa da gente". O objeto "casa" adquire o sentido de lar, provido de significados culturais e sociais entre o sujeito e o seu meio. Por sua vez, a segunda fala corrobora a ligação lugar e familiaridade, ao que o reassentado chama de estar "ambientado", além de se referir "a vida lá" e a "morte aqui". Este par de opostos reafirma São Sebastião do Soberbo como o lugar onde a vida se realiza, o lugar da fartura, e o Novo Soberbo como o espaço da morte e da doença, da falta e da escassez.

As manifestações de adaptação e segurança emergem, nos relatos dos reassentados, associadas ao "Soberbo Velho", locus de reminiscências aliadas a uma vida de trabalho, especialmente na/com a terra e o rio. Havia uma relação dos ribeirinhos com o Rio Doce abonando essa segurança: “... o rio era tão bom que trazia a lenha até nós”, “... do rio a gente tira tudo, areia, peixe, cascalho e ouro", e da terra “... nossas plantação de milho, feijão, cana de açúcar, café, verdura, fruta e capineira pro gado de leite”, “... sem água e sem terra nós não somos nada". A terra, o quintal, a horta, o jardim e outras benfeitorias que compunham o espaço da vida cotidiana dos atingidos, em São Sebastião do Soberbo, representam mais do que investimentos financeiros. Significam elementos simbólicos do espaço vivido, da sua lida, da própria história dos moradores, tendo, portanto, grande valor de uso para eles. ${ }^{11}$

O conceito de memória, pessoal ou coletiva integra o de lugar, pois nele "é possível perceber a fragmentação do mundo na dimensão do espaço,

11 "Os valores de uso refletem um misto de necessidades e reivindicações sociais, idiossincrasias, hábitos culturais, estilos de vida e similares [...]” (Harvey, 1980: 137). 
do indivíduo, da cultura, etc.” (Carlos, 1996: 15). No seu interior, guarda-se a história construída constantemente, sendo possível apreender o espaço pela memória, sentido e corpo (ibidem). Esse "mundo memória", segundo a expressão de Peguy, não deve ser esquecido: "É um mundo que amamos profundamente, memória olfativa, memória dos lugares da infância, memória do corpo, dos gestos da infância, dos prazeres" (De Certeau, 1996: 31). A história tem uma dimensão social manifesta no cotidiano das pessoas, no modo de vida, no uso, no relacionamento com o outro, com o lugar (Carlos, 1996: 26). A construção de uma rede de significados e sentidos a partir da história e da cultura produz uma identidade na qual as pessoas podem se reconhecer ou não.

O lugar bruscamente modificado pela introdução de uma barragem certamente será despojado dos referenciais concretos que sustentam a memória, o que, além de desenraizamento, promove a perda da identidade individual e coletiva dos atingidos (Bosi, 1994; 2003; Damiani, 2003). Deve-se atentar ainda à possibilidade da afasia, ${ }^{12}$ apresentada por Benjamin (2004) como uma vida sem reminiscência, ensejada pela sociedade moderna enquanto palco de catástrofes permanentes, que junto ao melancólico incita a inatividade, a prostração, etc.

Em consequência da desestruturação, do estranhamento e desenraizamento, a relação entre sujeito e espaço faz aflorar sentimentos negativos, como aversão, revolta, angústia, insegurança e tristeza diante do espaço do reassentamento, como ilustra o seguinte depoimento:

Depois que eles despejou a gente aqui minha vida não é mais a mesma, nem minha saúde. [...] tomo remédio pra depressão, pra dormir. Eu tô toda complicada, antes eu era mulher que buscava a minha lenha. [...] E o que que a gente tem aqui? Tem desespero. A gente tá sofrendo aqui [...]. Eu tô pedindo a Deus pra me tirá do mundo, deito e não durmo fico pensando nessa desgraceira toda, dá é vontade de morrer [...]. Se eles [o consórcio] vierem aqui vão apanhá de cabo de vassoura, eu odeio eles [...] e odeio tudo que eles construíram para gente, esse reassentamento, essa casa, tudo [...]. Eu tenho vergonha na cara. Eu não gosto e não aceito eles dentro da minha casa [...]. Eu vou morrer e não vai demorá... (Entrevista com reassentada, 45 anos, em 24.02.07)

12 A afasia corresponde a um transtorno cognitivo caracterizado pela inabilidade em compreender ou expressar a linguagem nas formas escrita ou falada. Benjamin (2004) associou o termo a uma postura de emudecimento por parte dos indivíduos que possuem uma vivência permeada por choques. 
A aversão dirigida ao reassentamento, embora menos exacerbada, pode evocar a sensação de não adaptação, o desejo de mudança, de residir em outro local e a própria migração, já efetivada, de algumas famílias:

O problema foi que eu não me dei com a mudança, até hoje eu não me acostumei com isso aqui. (Entrevista com reassentada, 75 anos, em 24.02.07)

Se eles [o consórcio] tivessem me dado um dinheiro que presta eu tinha ido pra um lugar bem diferente daqui. Eu tinha saído daqui mesmo. Muita gente já alugou a casa, uns já até venderam. Tem casa fechada, sem ninguém morando [...] É, o povo desanima e sai fora. (Depoimento de reassentado de Novo Soberbo, em 15.03.07)

Por outro lado, a resignação e aceitação aparecem, sem no entanto denotarem satisfação com o Novo Soberbo:

Deu uma mudança geral na vizinhança, a renda principalmente caiu muito, mas em qualquer lugar as pessoas vão vivendo... A gente não vai dizer que aqui não tem coisa que melhorou. Mas é aquele negócio, você passava numa casa simples, mas tinha mais coisa pro pessoal fazer e aqui já não tem. (Entrevista com reassentado, 62 anos, 25.02.07)

Eu já me acostumei com aqui. Foi difícil, mas o tempo ajuda. [...] Preferi, preferi mesmo, eu não sei, mas acho que São Sebastião do Soberbo era melhor. Mas pra mim a única coisa que falta agora é a reativação econômica. (Entrevista com reassentado, 27 anos, 27.02.07)

Resta saber qual é a positividade dessa resignação, manifesta pela acomodação/assimilação de um espaço imposto e pelo passar do tempo. Afinal, em quase oito anos de residência no reassentamento novas relações e experiências têm sido articuladas e também incorporadas ao espaço, em sua singularidade e diversidade.

Mas, para além dos sentimentos de resignação, observam-se tentativas de superação da produção espacial totalitária, através das práticas sociais, do discurso e das tentativas concretas de apropriação (que não se desvinculam dos saberes e da cultura, como forma de subversão da realidade imposta). De fato, a relação dialética entre sujeito e espaço pode manifestar-se, uma vez que o espaço condiciona os sujeitos que nele habitam, mas é também por eles condicionado, pois as práticas sociais podem se apropriar do espaço de formas diversas (Lefebvre, 2008). Declarações dos moradores revelam, 
apesar dos limites impingidos pelas condições materiais do reassentamento, algumas de suas formas de apropriação:

Temos fogão de lenha, o Consórcio quem fez depois de muita luta. Tem serpentina também, porque a energia é muito cara e nós já era acostumado com a água morna da serpentina. O problema é a lenha né, que tem de comprá. (Entrevista com reassentada, 60 anos, em 25.02.07)

Eu tenho galinha no quintal de casa, e planto mesmo nesse pedacinho aí que você tá vendo... Isso aqui é quiabo, ali é abóbora, tomate, alface, couve... É muito pouca terra, mas se é o que tem... A gente dá um jeito de fazer o que dá né. Até na frente de casa eu planto... você viu lá? Plantei tomate e uns pé de jiló junto com as rosa. [...] o fundo de casa é onde eu mais fico, porque é onde eu distraio mais. (Entrevista com reassentada, 51 anos, em 27.02.07)

Assim, algumas práticas de ruralidade permaneceram face à realocação de um ambiente rural para outro com formato urbano. Observou-se o uso de cavalos como principal meio de locomoção, galinhas dentro de casa e animais como bodes amarrados nas grades das residências, todos resíduos de ruralidade (Lefebvre, 1975). Ao utilizarem o fogão de lenha, a serpentina e a toda (mas pouca) terra disponível "no fundo" e "na frente" da casa para plantar, os atingidos revalidaram a sua cultura, as suas práticas e ressignificaram esse espaço, criando lugares que os remetem ao modo de vida anterior, no "Soberbo Velho". Esses resíduos, enquanto tentativas concretas de produção e reprodução das relações de subsistência dos atingidos, podem ser interpretados como formas de resistência ou de reexistência: "a vida contraditória invade e perturba a racionalidade redutora imposta. Nesse momento, mesmo que residualmente, existe apropriação" (Damiani, 2001: 54).

Os sistemas simbólicos são frequentemente criados e recriados nas/ /pelas práticas sociais, porque a ação humana não se conforma especificamente às representações. Assim, os reassentados, através da apropriação/ /ressignificação dos espaços no Novo Soberbo, conseguem, em alguns momentos, superar a conformação espacial erigida das representações do Consórcio Candonga:

... a gente vai adaptando o lugar ao que a gente precisa, né? Como cê tá vendo aí eu tenho um viveiro de galinha, umas verdura, a laranja ainda não deu porque tá pequena ainda e esse paiol que eu mesmo fiz. Aí eu guardo minhas ferramenta de trabalho e outras tralhas. (Entrevista com reassentado, 54 anos, 27.02.07) 
Neste sentido, "há muito mais coisas determinando nossa vivência do espaço do que o 'capital"” (Massey, 2000: 179), embora em alguns contextos e momentos ele pareça flutuar sobre tudo e todos. Em Candonga, é inegável que as relações de produção e o movimento do capital interfiram decisivamente nas condições e no modo de vida. A prevalência de espaços redutores, ressecados, torna as formas de apropriação e os resíduos de ruralidade expressão de contradições, ao mesmo tempo em que possibilitam o surgimento de mobilizações e resistências que questionem/neguem a redução do vivido ao concebido. Novos significados atribuídos ao reassentamento, dentre os quais o da "luta", sempre revigorarão as possibilidades de cumprimento dos direitos dos atingidos:

O reassentamento pra mim hoje é luta. [...] Lutando a gente conseguiu melhorar um pouco as coisas por aqui e lutando é a chance da gente consegui fazer tudo mudar pra melhor. (Entrevista com reassentado do Novo Soberbo, militante do MAB, 47 anos, em 28.02.07)

Pra mim não faz sentido ficar aqui [no reassentamento], o único sentido que eu vejo é ficar pra lutar. O povo está unido, tem nós aqui do Novo Soberbo, o pessoal das outra comunidade também, de Jerônimo, de Santana do Deserto, Marimbondo... Todos pra lutar junto com o MAB. Nós não somos pobres coitados, somos fortes porque somos unidos, porque participamos de um movimento do povo. (Depoimento de reassentado do Novo Soberbo, em 15.03.07)

No contexto da pesquisa, o Novo Soberbo configura-se como um "espaço de resistência" onde, conforme Santos (2000: 114), os expropriados "não se subordinam de forma permanente à racionalidade hegemônica e, por isso, com frequência podem se entregar às manifestações que são a contraface do pragmatismo". Assim, os conflitos e contradições, combustíveis à politização desse processo, certamente desencadearam alternativas contra-hegemônicas. A força política tende a reatestar-se como um importante instrumento proveniente das ações e das práticas sociais ligadas às possibilidades concretas extraídas da luta social, que se materializa na construção da identidade de atingido. Ao ressignificarem o reassentamento como lugar de luta, os atingidos corroboram os amplos sentidos do lugar, na tentativa de obter do Novo Soberbo, além dos meios materiais e simbólicos para que se estabeleçam e se fixem, um futuro digno. 


\section{Referências bibliográficas}

Acselrad, Henri (2004), "As práticas espaciais e o campo dos conflitos ambientais”, in Henri Acselrad (org.), Conflitos ambientais no Brasil. Rio de Janeiro: Relume Dumará/Fund. Heinrich Böll.

Acselrad, Henri; Pádua, José Augusto; Herculano, Selene (2004), Justiça ambiental e cidadania. Rio de Janeiro: Relume Dumará.

Barros, Juliana Neves; Sylvestre, Marie-Eve (orgs.) (2004), "Relatório Atingidos e Barrados - As violações de direitos humanos na hidrelétrica Candonga”. Rio de Janeiro e Ponte Nova, novembro.

Benjamin, Walter (2004), A origem do drama trágico alemão. Lisboa: Assírio \& Alvim.

Bermann, Célio (2007), "Impasses e controvérsias da hidreletricidade", Estudos Avançados, 59(21), 139-153, Jan./Abril.

Berman, Marshall (1986), Tudo que é sólido desmancha no ar: a aventura da modernidade. São Paulo: Companhia das Letras.

Bosi, Ecléa (1994), Memória e sociedade: lembranças de velhos. São Paulo: Companhia das Letras [3. ${ }^{a}$ ed.].

Carlos, Ana Fani (1996), O lugar no/do mundo. São Paulo: Hucitec.

Chaú, Marilena (1981), Cultura e democracia o discurso competente e outras falas. São Paulo: Editora Moderna.

COPAM - Conselho de Política Ambiental de Minas Gerais (2002), Transcrição da reunião de 14.03.03 da Câmara de Atividade de Infra-Estrutura (CIF), Belo Horizonte.

Damiani, Amélia (2001), "As contradições do espaço: da lógica (formal) à (lógica) dialética, a propósito do espaço”, in Amélia L. Damiani; Ana Fani A. Carlos; Odette C. de L. Seabra (orgs.), O espaço no fim de século: a nova raridade. São Paulo: Contexto.

Damiani, Amélia (2003), “A geografia e a construção da cidadania”, in Ana Fani Carlos (org.), A geografia na sala de aula. São Paulo: Contexto.

De Certeau, Michel (1996), A invenção do cotidiano. Petrópolis: Vozes.

Dos Santos, José Vicente Tavares (1992), "Violência no campo: o dilaceramento da cidadania”, Reforma Agrária, 22(1), 4-11, Jan./abril.

FEAM - Fundação Estadual do Meio Ambiente (2004), "Relatório Técnico - DIENI 008/2004. Processo n. ${ }^{\circ}$ 130/1998/005/2003”, Belo Horizonte.

Hall, Stuart (2006), A identidade cultural na pós-modernidade. Tradução de Tomaz Tadeu da Silva e Guacira Lopes Louro. Rio de Janeiro: DP \& A [11. ed.].

Harvey, David (1980), Justiça social e a cidade. Tradução de Armando C. da Silva. São Paulo: Hucitec.

Jornal Estado de Minas (2005), "Minas ganha novas usinas hidrelétricas”, 21.08.2005.

IBGE - Instituto Brasileiro de Geografia e Estatística (2010), Censo Demográfico 2010.

Consultado a 05.08.2010, em http://censo2010.ibge.gov.br/.

Lefebvre, Henri (1975), De lo rural a lo urbano. Barcelona: Ed. Península. 
Lefebvre, Henri (1991), O direito à cidade. Tradução de Rubens E. Frias. São Paulo: Ed. Moraes.

Lefebvre, Henri (2000), La production de l'espace. Paris: Ed. Anthropos [4. 'ed.].

Lemos, Chélen Ficher (1999), "Audiências Públicas, participação social e conflitos ambientais nos empreendimentos hidroelétricos: os casos de Tijuco Alto e Irapé”. Dissertação de mestrado apresentada ao Instituto de Pesquisa e Planejamento Urbano e Regional da Universidade Federal do Rio de Janeiro, Brasil.

Malard, Maria Lúcia (2006), As aparências em arquitetura. Belo Horizonte: Editora da UFMG.

Marcuse, Herbert (1964), A ideologia da Sociedade Industrial. Rio de Janeiro: Zahar.

Massey, Doreen (2000), "Um sentido global do lugar", in Antônio Arantes (org.), O espaço da diferença. Campinas: Papirus.

Oliveira, Raquel (2005), Conflitos socioambientais no Licenciamento da Usina Hidrelétrica de Murta: a luta pelo sentido e o destino do território no Médio Jequitinhonba - MG. Belo Horizonte: UFMG/Departamento de Sociologia e Antropologia (Monografia).

Pinto, Vero Franklin Sardinha (2005), "Conflitos Socioambientais em Licenciamento de Hidrelétricas: o caso de Candonga”. Dissertação de Mestrado em Geografia, apresentada à Instituto de Geociências da Universidade Federal de Minas Gerais, Belo Horizonte, Brasil.

Rancière, Jacques (1996), “O dissenso”, in Newton Bignotto; Adauto Novaes (orgs.), A crise da razão. São Paulo: Companhia das Letras.

Rebouças, Lídia Marcelino (2000), O Planejado e o Vivido: o reassentamento de famílias ribeirinhas no Pontal do Paranapanema. São Paulo: Annablume/FAPESP.

Said, E. (1990), "Narrative, Geography and Interpretation”, New Lef Review, 180, 81-100.

Santos, Milton (2000), Por uma outra globalização: do pensamento único à consciência universal. Rio de Janeiro: Record [2. ${ }^{\mathrm{a}}$ ed.].

Santos, Milton (2008), A natureza do Espaço: técnica e tempo - razão e emoção. São Paulo: Edusp [4. ${ }^{\mathrm{a}}$ ed.].

Thompson, Paul (1992), A voz do passado: história oral. Rio de Janeiro: Paz e Terra.

Vainer, C. B. (1993), "População, meio ambiente e conflito social na construção de hidrelétricas”, Revista Travessia, 183-207, Jan/Fev.

Vainer, C. B. (2007), "Recursos hidráulicos: questões sociais e ambientais", Estudos Avançados, 59(21), 119-137, jan./abril.

Vieira, Ubiratan G. (2000), "Limites do poder comunicativo e da argumentação técnica no licenciamento ambiental de hidrelétricas em Minas Gerais". Tese de Pós-graduação em Extensão Rural (título de Magister-Scientiae) da Universidade Federal de Viçosa, Minas Gerais, Brasil.

Zhouri, Andréa; Laschefski, Klemens; Pereira, Doralice Barros (orgs.) (2005), A insustentável leveza da política ambiental - desenvolvimento e conflitos socioambientais. Belo Horizonte: Autêntica. 